\title{
"Latin America": entre o politicamente correto e o conceitualmente inadequado
}

\section{"Latin America": between the politically correct and the conceptually inadequate Diogo da Silva Roiz}

\section{A história do conceito de "Latin America" nos Estados Unidos Foão Feres $\mathcal{F r}$. Bauru: Edusc-Anpocs, 2005, 317p.}

Apenas recentemente a história conceitual começou a ser um campo de investigação promissor na pesquisa histórica brasileira. Prova disso, mesmo que parcial, é que apenas em 2001 se fez a tradução do livro Crítica e crise de Reinhart Koselleck, a famosa tese do autor publicada originalmente em 1959, e em 2006,

Diogo da Silva Roiz é doutorando em História pela Universidade Federal do Paraná (UFPR), Brasil, bolsista do CNPq e professor dos cursos de História e de Ciências Sociais na Universidade Estadual de Mato Grosso do Sul (UEMS), Campus de Amambai, em afastamento integral para estudos (diogosr@yahoo.com.br). Resenha recebida em 13 de maio de 2009 e aprovada para publicação em 27 de agosto de 2009. 
de seu grande livro Futuro passado: contribuição à semântica dos tempos históricos, originalmente um conjunto de ensaios reunidos em livro em 1979, com os quais o autor se tornou uma referência internacional nos estudos sobre a história conceitual. Tudo indica que o momento tem sido fértil para que ocorram as primeiras apropriações deste importante autor nos estudos históricos desenvolvidos no Brasil neste campo de pesquisa.

Muito embora João Feres Jr. tenha defendido seu PhD nos Estados Unidos (pesquisa equivalente ao doutoramento no Brasil), a partir de sua estadia de oito anos em Nova York, após defender sua dissertação de mestrado em filosofia política na Unicamp, seu trabalho foi um exemplo de uso bem-sucedido da obra de Reinhart Koselleck para fazer uma história conceitual do termo Latin America.

Desde 2003 Feres Jr. é professor de ciência política no Instituto Universitário de Pesquisas do Rio de Janeiro (Iuperj), e em 2004 sua tese recebeu o prêmio de melhores teses do ano no concurso da Edusc-Anpocs, na área de Ciência Política, cuja função é tornar públicas as pesquisas com o financiamento integral de sua publicação. No Brasil, é um dos coordenadores do projeto de História Conceitual Comparada do Mundo Ibérico, que inclui quatro outros países (Espanha, Argentina, Colômbia e México), e há cinco anos coordena, com Marcelo Jasmin, o grupo de História das Ideias e Conceitos Políticos, que tem promovido encontros regulares para a discussão de aspectos metodológicos e de questões cruciais da história conceitual.

Por essa e por outras razões, seu texto é um bem-sucedido exemplo de uso crítico da obra de Reinhart Koselleck para elaborar uma história conceitual de Latin America. Diz ele, para justificar tal estudo, que:

Os termos usados para identificar povos, culturas e regiões do mundo têm sido, nos últimos tempos, sujeitos à revisão crítica. Isso é particularmente verdadeiro na sociedade americana, em que os temas do multiculturalismo e do respeito à diferença se tornaram candentes (...). É interessante notar, contudo, que algumas denominações étnicas escapam dessa onda revisionista. Provavelmente isso se deu porque elas não são explicitamente insultantes. Esse é o caso de Latin America, um termo amplamente usado no inglês contemporâneo e que, portanto, parece ter passado no teste do politicamente correto da sociedade americana. Entretanto, acredito que o conceito de Latin America tem sido de fato um instrumento de representação distorcida daqueles que os americanos percebem como Latin Americans e, consequentemente, um meio que contribui para o tratamento assaz desigual historicamente dispensado a essa gente, tanto àqueles que vivem no sul do Rio Grande quanto àqueles que vivem nos EUA como imigrantes "latinos". (p. 9-10) 
Nesse sentido, sua pesquisa procurou circunscrever o que quer dizer $L a-$ tin America e quais seus usos no inglês americano. Com base na análise dos principais significados atribuídos ao termo, tanto na linguagem comum quanto "nos textos produzidos por especialistas das ciências sociais", definiu a seguinte tese para a sua proposta de investigação:

(...) de que Latin America tem sido definida no inglês americano, tanto na linguagem comum quanto nos textos especializados, como o oposto de uma autoimagem glorificada da America (...) demonstrarei essa tese através de um experimento semântico parcimonioso que requer apenas um mínimo de informação histórica (...) tratarei de mostrar que, no inglês usado hoje em dia, há uma assimetria fundamental entre a percepção do Eu coletivo americano e do Outro Latino Americano. (p. 10)

Para demonstrar adequadamente sua tese, Feres Jr. preocupou-se inicialmente "com a procura de um termo semanticamente assimétrico ao conceito de Latin America em inglês". Como ele explica, nem North America, que possui um caráter mais geográfico, nem Anglo-Saxon America, com maior ligação linguística, formavam correspondentes assimétricos adequados à comparação com Latin America, o que foi averiguado com o termo Germanic America, ou Teutonic America. Mesmo que de uso corrente no século XIX, após as guerras mundiais das primeiras décadas do século XX este termo entrou em desuso. No entanto, ele é um termo assimétrico mais pertinente que Anglo-Saxon America (que é de uso mais corrente na língua norte-americana hoje) por trazer "conotações racistas claras". "Mas se essa intuição está correta, se Latin America também é um termo chave de um discurso racista, esse discurso deve ter uma natureza diferente do pangermanismo ou do anglo-saxonismo, pois não aparece de maneira explícita". De modo que uma "tese auxiliar desse trabalho é a de que o discurso das ciências sociais contribui para esse ocultamento" (p. 13).

A forma clara e direta com que o autor faz a exposição de sua tese na pesquisa talvez oculte, num primeiro olhar, o trabalho árduo e cansativo que sua comprovação acarretou, ainda que a maneira com que ele demonstra seus argumentos possa parecer "óbvia”. Tal como ele indica:

O leitor atento já deve ter corretamente adivinhado que muitos dos significados pejorativos identificados na análise dos verbetes do $O E D$ e nos textos de Martin e Smith serão revelados pela análise do significado do conceito, seja na linguagem comum, seja nos discursos 


\section{Diogo da Silva Roiz}

sociocientíficos (...). Contudo, mais interessante e revelador não é saber que eles lá estão, mas compreender em que momento histórico eles aparecem ou são deixados de lado, entender as conexões entre uma determinada definição histórica de Latin America e as ações dos homens que dela se serviram, verificar quais significados resistiram ao passar do tempo e através de qual retórica, e saber quais as implicações do uso do termo no passado e nos dias de hoje. São esses conhecimentos que o percurso do trabalho presente pretende revelar (p. 27).

O que o leitor tem, assim, “em suas mãos” é um livro sério e criterioso, muito bem pensado e formulado. Não há como negar, desde já, que a sua contribuição é dupla e evidente: contribui diretamente, de um lado, para o avanço dos estudos sobre a história conceitual produzidos no Brasil, e, de outro, para que possamos constatar que a aparente conotação politicamente correta atribuída pelos norte-americanos a Latin America e a Latin Americans, na verdade, camufla e condiciona a uma suavização as concepções racistas inerentes, que os termos inicialmente ocultam na linguagem comum e nos estudos especializados, e que servem de base para os textos usados nas universidades norte-americanas ensinarem a história da América Latina a seus alunos. De acordo com ele:

Esse não é, contudo, simplesmente um livro de história. A história conceitual praticada aqui está intimamente imbricada com um projeto crítico de desvendamento do mundo presente com vistas a transformá-lo. Portanto, a questão do significado moral da definição do Outro como mera negação da autoimagem de um Eu coletivo deve preceder a própria análise histórica do caso em questão. A teoria do reconhecimento me parece ser um bom ponto de partida para a discussão das implicações morais do problema em questão, uma vez que seu tema é a constituição reflexiva da identidade através da análise fenomenológica do encontro entre Eu e Outro (p. 23-4).

Num trabalho de ciência política dividido em sete capítulos muito bem articulados e escritos, não é de se estranhar que o autor comece por estudar e por definir, no primeiro capítulo, uma tipologia das formas de desrespeito do "Eu coletivo norte-americano" para com o "Outro latino americano". E isso é feito a partir de uma reformulação e ampliação crítica da história conceitual preconizada por Reinhart Koselleck em seu livro Futuro passado (1979), no qual este discutiu a noção de contraconceito assimétrico, e de uma síntese crítica da teoria do 
reconhecimento de Axel Honneth, apresentada em sua obra The struggle for recognition: the moral grammar of social conflicts (1995).

Essa tipologia se caracteriza, desse modo, por analisar: a) a oposição assimétrica cultural; b) a oposição assimétrica temporal; c) e a oposição assimétrica racial. Para Feres Jr., a “oposição assimétrica é uma das formas semânticas que o desrespeito pode assumir quando articulado através da linguagem, e uma das mais radicais, pois o Eu vê no Outro somente reflexões invertidas de sua própria autoimagem. Portanto, essa tipologia de formas de oposição assimétrica é também uma tipologia de formas de desrespeito", com as quais, seja no senso comum, seja nos estudos especializados, avaliam, mesmo que implicitamente, os latino-americanos como inferiores aos norte-americanos.

Para comprovar essa dedução, no capítulo seguinte, o autor evidencia como surgiram tais conceitos na história dos Estados Unidos, promovendo um estudo do senso comum, para demonstrar quais usos de Latin America e Latin Americans foram e ainda são feitos. Com base em sua tipologia, ressalta como as oposições assimétricas cultural, temporal e racial se desenvolveram e, às vezes, coexistiram no decorrer dos séculos XIX e XX, expressando formas de desrespeito ora explícitas, ora implícitas, à Latin America e aos Latin Americans. Nesse aspecto, não se limita às expressões linguísticas e aos seus significados, mas também analisa a iconografia que foi produzida no período. Pode-se argumentar aqui que, embora o autor não tenha verificado como os EUA, nas primeiras décadas do século XX, já impunham esses discursos e imagens aos países latino-americanos, muitas pesquisas produzidas no Brasil (e em outros países) têm se preocupado em demonstrar que tipos de discurso, artigos e imagens eram projetados em jornais e revistas, pelos norte-americanos (enquanto civilização racional, protestante, desenvolvida e imperialista), sobre os latino-americanos (na maioria das vezes identificados como uma civilização irracional, católica, ibérica e subdesenvolvida).

Para o autor, o "estudo dessa modalidade discursiva, tão importante para as sociedades de hoje, não tem merecido grande atenção por parte da história conceitual”, mas "a comparação entre a semântica do conceito no discurso das ciências sociais e na linguagem comum constitui uma oportunidade ímpar de análise e crítica" (p. 77-8). Não foi, então, por acaso que nos quatro capítulos seguintes Feres Jr. passou em revista a semântica do conceito de Latin America e os seus diferentes usos nas ciências sociais, percorrendo o imperativo da modernização, as discussões sobre a estabilização política, os estudos sobre dependência (mesmo considerando que neste caso houve uma apropriação, principalmente, das obras de Fernando Henrique Cardoso, Enzo Faleto e André Gunder Frank pelos estudiosos norte-americanos) e os estudos do corporativismo (com atenção especial para a obra de Howard Wiarda). Da mesma forma, usou sua tipologia, constatando formas semelhantes de desrespeito, antes já expressos na 
linguagem comum e agora visualizados também na modalidade discursiva socio-científica. Destaca que houve uma explosão desses estudos, após a Revolução Cubana de 1959, que, despertando os norte-americanos para o "perigo do comunismo" na América Latina, permitiu a formação de grupos de pesquisa e centros especializados nesses estudos nos EUA. De acordo com seu apêndice número 1 (apresentado à página 287), enquanto entre 1951 e 1960 houve 91 publicações no gênero, na década seguinte, entre 1961 e1970, o número passou para 328, e entre 1991 e 2000, para 502.

No último capítulo do livro, Feres Jr. se preocupou em saber quais eram os livros-texto mais lidos e usados nas disciplinas sobre a história da América Latina oferecidas nos cursos de graduação das universidades norte-americanas. Ele observa, principalmente, as obras que figuravam na bibliografia básica das disciplinas, dando ênfase aos mais citados. O capítulo é verdadeiramente primoroso, pois além de fazer um recenseamento exaustivo, ocupa-se também dos principais usos atribuídos por esses livros-texto aos termos Latin America e Latin Americans. Desse modo, a "história do conceito de Latin America no inglês americano revela a presença persistente de oposições assimétricas estruturando seu campo semântico", tendo sido definida "implícita ou explicitamente, em oposição a uma imagem idealizada da America (Estados Unidos)". E, ainda "que o foco central do livro tenha sido o discurso sociocientífico, o campo semântico do conceito na linguagem comum foi estabelecido, entre outras finalidades, para servir-lhe de parâmetro de comparação", até porque, ao "passo que as oposições assimétricas temporal e cultural foram mantidas ou até mesmo amplificadas, a oposição assimétrica racial foi, no mais das vezes, silenciada" (p. 280-1). Por fim:

(...) temos a longa história das relações políticas dos EUA com seus vizinhos do sul (...). O problema mais sério e profundo do discurso dos Latin American Studies está na própria semântica do conceito, estruturado pelas oposições assimétricas que definem Latin Americans como seres destituídos de agência e de razão, como coisas (...). Assim percebemos que a negação do reconhecimento denotada pela semântica do conceito vai muito além do mero uso de uma linguagem insultosa, ela traduz-se em ações das mais concretas de negação da autonomia desse outro da America na América. Essa negação do reconhecimento só é amplificada pelo raciocínio sinedóquico que consistentemente ignora a maneira como as pessoas experimentam suas vidas como membros de uma comunidade política, de uma sociedade (p. 286).

Esse livro oferece, consequentemente, uma interpretação consistente e articulada da maneira como a América Latina e os latino-americanos foram his- 
toricamente analisados pela linguagem comum e pelos estudos norte-americanos especializados. Mostra como uma terminologia, ainda que considerada politicamente correta pela sociedade que a utiliza, pode ser conceitualmente inadequada, por guiar um conjunto de formas de desrespeito (cultural e racial) inerentes às suas acepções semânticas. Pode-se até questionar a amostra selecionada, por não cobrir todas as ciências sociais ou todos os textos das áreas selecionadas e analisadas na pesquisa, assim como se pode alegar que sua interpretação do senso comum não revela a totalidade do processo, nem todos os seus diferentes significados. Mas não há como negar que este é um livro pioneiro sobre o tema, sendo ao mesmo tempo sugestivo e instigante. Sem dúvida alguma, ele será uma referência, por rever um conhecimento herdado e permitir ao leitor (também) transformá-lo. 